\title{
Identification of MicroRNAs With In Vivo Efficacy in Multiple Myeloma-related Xenograft Models
}

\author{
ULRICH H. WEIDLE and ADAM NOPORA
}

Roche Pharma Research and Early Development, Roche Innovation Center Munich, Penzberg, Germany

\begin{abstract}
Background/Aim: Multiple myeloma is a B-cell neoplasm, which can spread within the marrow of the bones forming many small tumors. In advanced disease, multiple myeloma can spread to the blood as plasma cell leukemia. In some cases, a localized tumor known as plasmacytoma is found within a single bone. Despite the approval of several agents such as melphalan, corticosteroids, proteasome inhibitors, thalidomide-based immuno-modulatory agents, histone deacetylase inhibitors, a nuclear export inhibitor and monoclonal antibodies daratuzumab and elatuzumab, the disease presently remains uncurable. Materials and Methods: In order to define new targets and treatment modalities we searched the literature for microRNAs, which increase or inhibit in vivo efficacy in multiple-myelomarelated xenograft models. Results and Conclusion: We identified six up-regulated and twelve down-regulated miRs, which deserve further preclinical validation.
\end{abstract}

Multiple myeloma (MM) is a B-cell malignancy characterized by an excess of monoclonal plasma cells in the bone marrow (BM) (1). In 2019, the incidence of MM in the US was 32,000 new cases and 13,000 deaths (2). Regarding pathogenesis, it has been shown that monoclonal gammopathy of undetermined significance (MGUS), a premalignant state of the disease, progresses to MM which

This article is freely accessible online.

Correspondence to: Adam Nopora, Roche Innovation Center Munich, Roche Diagnostics GmbH, Nonnenwald 2, D-82372 Penzberg, Germany. Tel: +49 8856602552, e-mail: adam.nopora@roche.com and Ulrich H. Weidle/Adam Nopora, Roche Innovation Center Munich, Roche Diagnostics GmbH, Nonnenwald 2, D-82372 Penzberg, Germany, Tel: +498856602552, e-mail weidle49@tonline.de

Key Words: Antisense-oligonucleotides, microRNA delivery, microRNA mimetics, locked nucleic acids, treatment resistance, multiple myeloma, review. is associated with osteolytic bone lesions in most patients (3). MM homes to the BM by binding to adhesion and extracellular matrix proteins (4). Considerable variability in MM evolution has been observed in patients with MM due to evolution of different dominant subclones (5). In the majority of patients translocations which deregulate oncogenes such as cyclin D1 and D3, fibroblast growth factor receptor 3 (FGFR3), nuclear protein multiple myeloma SET (MMSET) or transcription factors such as c-MYC and c-MAF have been identified (6). Despite approval of several agents for treatment, the disease is presently incurable $(7,8)$. Among the approved agents are chemotherapeutics such as melphalan, corticosteroids dexamethasone (dex) and prednisone, immuno-modulatory agents such as thalidomide, lenalidomide and pomalidomide, proteasome inhibitors bortezomib, carfilzomib and ixazomib, histone deacetylase (HDAC) inhibitors such as panobinostat and nuclear export inhibitor selinexor $(7,8)$. In addition, two monoclonal antibodies (mabs) have been approved: daratuzumab, directed against cluster of differentiation 38 (CD38) and elatuzumab targeting SLAM family member 7 (SLAMF7) $(9,10)$. For palliative treatment of osteolytic bone disease, bisphosphonates, such as pamidronate and mab denosumab have been approved (11). Immuno-therapy approaches based on bispecific antibodies and chimeric antigen receptor (CAR) T-cells with focus on B cell maturation antigen (BCMA) as a target are ongoing $(12,13)$. Nevertheless, due to incurabilty of the disease with presently available agents, identification of new targets and treatment modalities are urgently requested. In this review, we focused on the role of microRNAs (miRs) in the context of the pathogenesis of $\mathrm{MM}$ with in vivo efficacy in MM-related models.

\section{Micro RNAs and Their Role in Oncology}

miRs are small noncoding RNAs in the range of 22 nucleotides (nts) in length. Their function is posttranscriptional mRNA silencing. This can be achieved by cleavage of the corresponding mRNA, destabilization of the 
target mRNA through shortening of the polyA tail and/or attenuation of its translation (14-16). At least 1,000 miRrelated genes transcribed by RNA polymerase II have been identified in humans (17). The biogenesis of miRs involves generation of pri- and subsequently of pre-miRs $(15,18)$. miRs are transcribed as RNAs forming short hairpins resulting in generation of pri-miRs. These are recognized by nuclear protein DiGeorge Syndrome critical region (DGCR8) which associates with ribonuclease DROSHA to form the MICROPROCESSOR complex $(15,18)$. The processing products are referred to as pre-miRs and are exported from the nucleus by exportin 5, a member of the karyopherin family. In the cytoplasm, DICER, an RNAse III enzyme, cleaves the premiRs yielding the $\mathrm{miR} / \mathrm{miR}^{*}$ duplex of about $22 \mathrm{nts}$ in length $(15,18)$. One strand is incorporated into the RNA-induced silencing complex (RISC) where miR and corresponding mRNA interact. Nts 2-7 of the miR, referred to as seed region, must be perfectly complimentary to the mRNA $(15,18)$. Multiple miRs can target the same mRNA and a single miR can target several different mRNAs (19). Therefore, miRs have the potential of reprograming malignant cells to benign cells (20).

The importance of miRs in oncology was shown in patients with chronic lymphatic leukemia (CLL) which is caused by loss of miRs 15a/16-1 functioning as tumor suppressors (TSs) by targeting B-cell lymphoma 2 (BCL2) $(21,22)$. Further work has identified miRs as regulators of oncogenes and TSs (23), tumor immunity (24) and metastasis (25-28). The role of miRs in MM is summarized in several reviews (29-31). In this review, we focus on miRs with in vivo efficacy in MM-related models in order to identify new targets and treatment modalities for treatment of MM.

\section{Up-regulated miRs With Efficacy in Myeloma-related In Vivo Models}

miR-17-5p affects iron transport. miR-17-5p (Figure 1) promotes cell proliferation and inhibits apoptosis in ARP1 and OCI MM cells (32). miR-17-5p transfected ARP1 cells exhibit increased tumor growth (TG) in comparison to control cells after subcutaneous implantation into immunedeficient mice (32). Ferroportin 1 (FPN1), a transmembrane protein, which transports $\mathrm{Fe}$ from the cytoplasm to the outside of the cell, was identified as a direct target of miR17-5p $(32,33)$. Decreased FPN1 has been shown to promote MM cell growth and osteoclast differentiation (34). Furthermore, decreased FPN1 correlates with bad prognosis in MM (34). FPN1 is regulated by hepsidin, a hormone produced in the liver. Hepsidin binds to FPN1 and limits its iron-efflux capacity (33).

miR-20a inhibits a zinc finger transcription factor. miR-20a (Figure 1), a member of the miR-17-92 cluster, is elevated
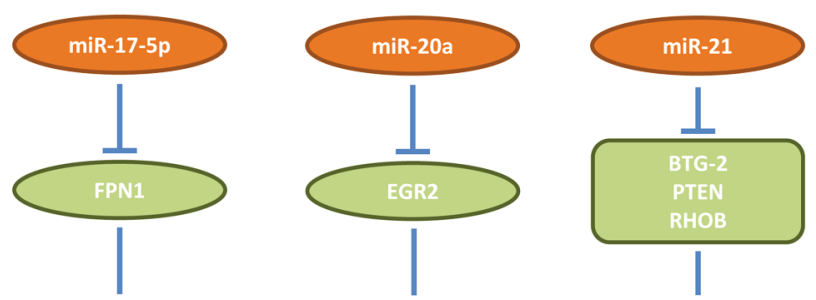

PROLIFERATION, INHIBITION APOPTOSIS
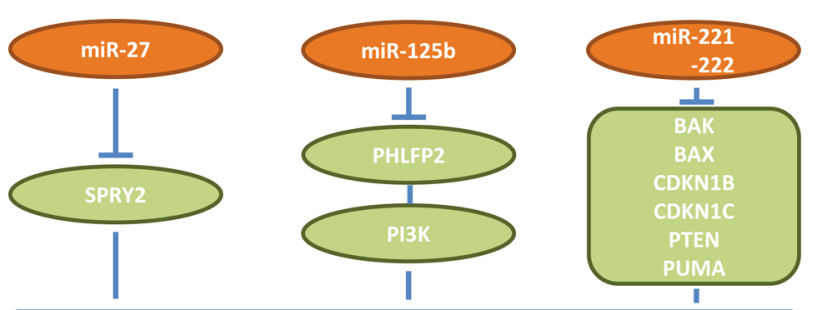

PROLIFERATION, INHIBITION APOPTOSIS

Figure 1. Up-regulated microRNAs promoting growth of multiple myeloma xenografts in preclinical in vivo models. The miRs are displayed according to their numerical designation. The corresponding targets are displayed. BAK: Pro-apoptotic protein BAK; BAX: BCL2-associated X protein; BTG2: BTG family member 2; EGR2: early growth response protein 2; FPN1: ferroportin 1; PHLPP2: PH domain and leucine rich repeat protein phosphatase; PI3K: phosphoinosite 3-kinase; PTEN: phosphatase and tensin homolog; PUMA: 53 up-regulator of apoptosis; CDKN1B: cyclindependent kinase inhibitor 1B; CDCN1C: cyclin-dependent kinase inhibitor 1C; RHOB: RAS homolog gene family, member $B$.

in the plasma of $\mathrm{MM}$ patients (35). miR-20a promotes proliferation of NCI-H929 and U266 cells (36). Intratumorally injected miR-20a mimetics into palpable tumors established by subcutaneous implantation of OPM2 MM cells promote TG in immune-deficient mice (36). Early growth response protein 2 (EGR2), a transcription factor with three $\mathrm{Zn}$ fingers, was identified as a direct target of miR-20a (36). EGR2 acts as a TS and inhibits tumor cell proliferation as well as metastasis and stimulates apoptosis $(37,38)$.

miRs affecting signaling and cell cycle

mir-27 inhibits proliferation-related pathways. miR-27 (Figure 1) is up-regulated in MM patients in comparison to $\mathrm{BM}$ derived from normal donors (39). Increased expression of miR-27 in MM patients predicts poor prognosis (39). miR-27 promotes proliferation, survival and motility of U266 and H929 MM cells (39). H929 cells treated with a miR-29 inhibitor display reduced TG after subcutaneous injection into the flanks of nude mice (39). Sprouty homolog 2 (SPRY2) has been identified as a direct target of miR-27 (39). SPRY2 acts as an inhibitor of the mitogen-activated 
protein kinase (MAPK) pathway in MM cells (40). SPRY2 also inhibits transforming growth factor $\beta$ receptor (TFG $\beta$ R), signal transducer SMAD2 and epidermal growth factor receptor (EGFR) signaling $(41,42)$.

miR-125b promotes AKT activation. Levels of miR-125b (Figure 1) are increased in plasma samples from MM patients compared to healthy controls (43). miR-125b stimulates proliferation and migration of $\mathrm{MM}$ cells and inhibition of miR-125b reduces the levels of phosphorylated signal transducer serine-threonine kinase AKT (43). Expression of a miR-125b inhibitor in MM cells suppresses TG in a xenograft model (43). Pleckstrin homology domain leucine-rich repeat protein phosphatase (PHLPP2) was identified as a direct target of miR-125b (43). PHLPP2 acts as a negative regulator of the phosphoinosite 3-kinase (PI3K) pathway (44).

miRs promoting growth of MM cells by simultaneous inhibition of several cell-cycle-, apoptosis-regulatory genes and tumor suppressors.

miR-21. miR-21 (Figure 1) expression correlates with disease progression in $\mathrm{MM}$ and inhibition of miR-21 affects growth, survival and clonogenicity of KMS-26, U-266 and OPM-2 MM cells (45). Enforced expression of miR-21 mimetics enhances proliferation of MM1S cells (45). miR-21 inhibitors abrogate the supporting activity of human BM stromal cells (45). Growth of palpable OPM-2 MM cells is inhibited by intra-tumoral injection of antisense oligonucleotides (ASO) directed against miR-21 (45). Phosphatase and tensin homolog (PTEN), ras homolog gene family member B (RHO B) and B-cell translocation gene 2 (BTG-2) were identified as targets of miR-21 (46). PTEN acts as a TS and has phosphatase-dependent and independent (scaffold) activities such as maintainance of genomic stability, modulation of cell survival, migration, proliferation and metabolism $(47,48)$. RHO B is a member of the RHO family of small GTPases which regulate actin stressfibers, cytoskeletal actin organisation and vesicle transport in cancer cells (49). BTG-2 regulates pre-B-cell differentiation through protein arginine N-methyltransferase 1 (PRMT1) mediated methylation of cyclin-dependent kinase 4 (CDK4) leading to cell-cycle arrest and limitation of preB-cell expansion (50). Furthermore, BTG-2 acts as a TS and is involved in adaptation to cellular stress (50).

miRs-221/222. miRs-221/222 (Figure 1) exhibit increased expression levels in BM of MM patients compared to BM from normal donors (51). In vitro, ASO and locked nucleic acid (LNA) 13 mer (LNA-i-miR-221) mediate significant anti-proliferative effects in OPM2 and NCI-H929 MM cells $(51,52)$. Palpable OPM2 xenografts in immuno-deficient mice treated intratumorally with unformulated or lipidemulsion particles of ASO directed against miRs 221/222 give rise to inhibited TG (51). Also, LNA-i-miR-221 induces anti-tumoral acitivity in sucutaneously implanted OPM2 xenografts after i.p. or i.v. injection (52). Only MM cells with $\mathrm{t}(4 ; 14)$ translocations are growth-inhibited by LNA-imiR-221 in vitro and in vivo (52). Up-regulation of canonic miR-221/222 targets such as PTEN, cyclin-dependent kinase inhibitors 1B and 1C (CDKN1B, CDKN1C), p53 upregulated modulator of apoptosis (PUMA) and impairment of AKT activation was observed after administration of LNA-i-miR-221 in vitro and in vivo (52). CDKN1B acts as a cell cycle inhibitor and TS and its inhibition promotes tumor cell proliferation $(53,54)$. CDKN1C functions as a TS and inhibits several G1 cyclin/CDK complexes resulting in inhibition of cell proliferation (55). PUMA has a proapoptotic function through interaction with anti-apoptotic BCL2 family members (56). The therapeutic potential of targeting the cell cycle and apoptotic pathways in MM are summarized in $(57,58)$.

\section{Down-regulated miRs Mediating In Vivo Efficacy in Myeloma-related Models}

miRs affecting angiogenesis. miRs-15a, -16. These are underexpressed in primary MM cells, established MM cell lines and in advanced stage MM patients in comparison to normal B-cells (Figure 2) (59). Vascular endothelial growth factor-A (VEGF-A) has been identified as a direct target of miRs-15a and -16 (59). RPMI-8226 cells transfected with pre-miR-15a or pre-miR-16a suppress pro-angiogenic activity of these cells, such as endothelial cell (EC) tube formation (59). Conditioned media from miR-15a or miR16a-transfected RPMI-8226 MM cells inhibit proliferation and chemotactic motility of bone marrow endothelial cells (BMEC) (59). RPMI-8266 cells transfected with lentivirus expressed miR-15a exhibit significant inhibition of TG after subcutaneous implantation into immune-deficient mice in comparison to control cells (59). Also, systemic delivery (i.v.) of synthetic miRs-15a/16 conjugated with neutral lipids inhibits growth of green fluorescent protein (GFP)-labeled RPMI-8266 cells in immuno-deficient mice as shown by reduced fluorescence in comparison to the control cell line (59). Interestingly, miRs-15a and -16 are deleted in CLL and are causative for this disease $(21,22)$. VEGF-A, the target of miRs-15a and -16 induces synthesis of interleukin 6 (IL6) in the endothelium of the micro-vasculature and in BM and acts a growth factor for MM cells (60). Increased BM-related angiogenesis in MM has been shown to be due to aberrant expression of angiogenic factors by MM cells (61). In line with these findings is the observation that approved agents for treatment of MM, such as bortezomid, thalidomide and its derivatives mediate anti-angiogenic activity (62-64). 


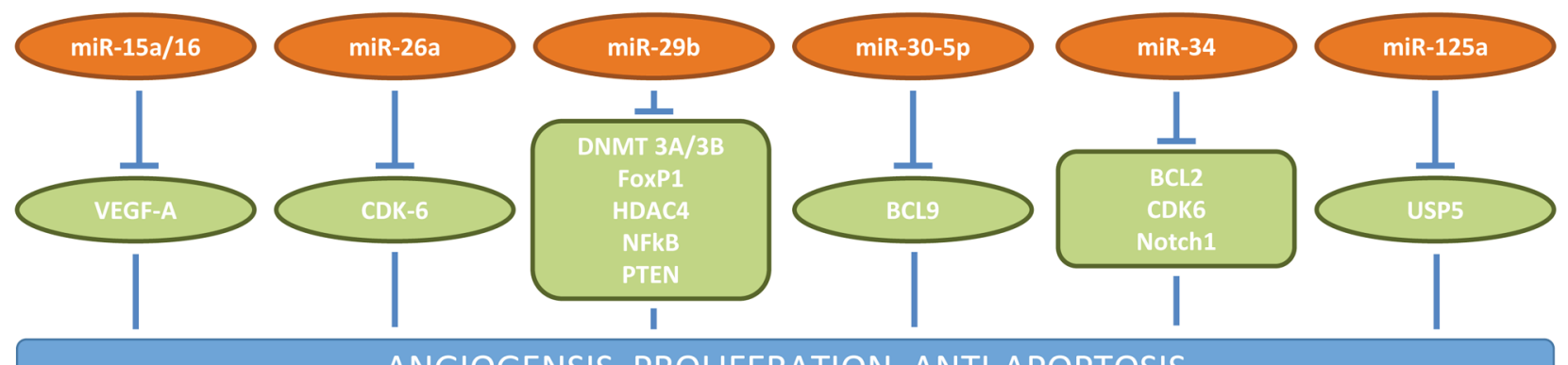

ANGIOGENSIS, PROLIFERATION, ANTI-APOPTOSIS
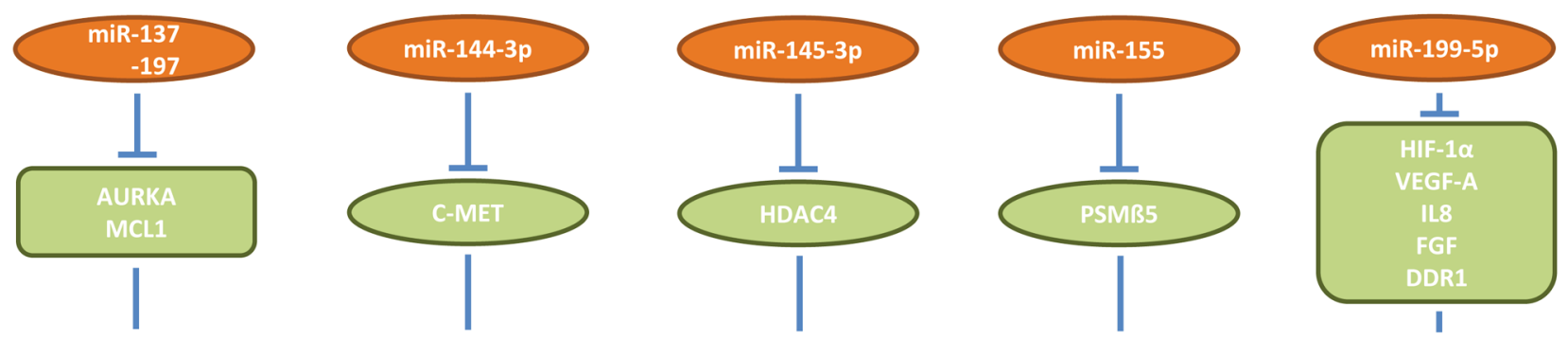

ANGIOGENSIS, PROLIFERATION, ANTI-APOPTOSIS

Figure 2. Down-regulated miRs inhibiting growth of multiple-myeloma-related xenografts in preclinical in vivo models. The miRs are displayed according to their numerical designation. The corresponding targets are displayed. AURKA: Aurora kinase A; BCL2: B-cell lymphoma 2; BCL9: $B$-cell CLL/lymphoma 9; CDK6: cyclin-dependent kinase 6; c-MET: transmembrane tyeosine kinase c-MET; DDR1: discoidin domain receptor family, member 1; DNMT3A/3B: DNA methyltransferase 3A/3B; FGF1: fibroblast growth factor 1; FOXP1: forkhead box protein P1; HDAC4: histone deacetylase 4; HIF-1 $\alpha$ : hypoxia inducible factor 1alpha; IL8: interleukin 8; MCL1: induced myeloid leukemia inducible factor 1alpha; NOTCH1: tyrosine kinase receptor notch 1; NFkB: nuclear factor kB; PTEN: phosphatase and tensin homolog; PSM $\beta 5$ : proteasome subunit $\beta$ type 5; USP5: uniquitin specific peptidase 25; VEGF-A: vascular endothelial growth factor-A.

miR-199-5p. miR-199-5p (Figure 2) decreases cell proliferation and increases apoptosis in MM cells under hypoxic conditions (65). miR-199-5p targets hypoxiainducible factor- $1 \alpha$ (HIF-1 $\alpha)$ which interferes with the $\mathrm{MM} / \mathrm{endothelial}$ cell (EC) loop promoting the basic events of the angiogeneic response (65). OPM2 MM cells transfected with synthetic miR-199-5p show reduced expression of angiogenic factors such as VEGF-A, interleukin 8 (IL8) and basic fibroblast growth factor (bFGF) and their conditioned media reduce EC migration (65). Enforced expression of miR-199-5p in MM cells represses discoidin domain receptor 1 (DDR1), which is involved in promoting cancer cell proliferation, drug resistance, angiogenesis and metastasis (65-67). DDR 1 is a predicted target of miR-199-5p (68). Growth of subcutaneously injected, palpable NCI-H929 MM cells was significantly inhibited after intratumoral injection of miR-199-5p formulated as neutral emulsion particles (65). It was also shown that miR-199-5p induces adhesion of MM cells to hypoxic BM stromal cells (BMSCs) (65). HIF-1 $\alpha$, the major target of miR-199-5p, plays a pivotal role in adaptation of tumor cells to nutrient-deprived conditions by up-regulation of transcription of several hypoxia-inducible oncogenic factors and acts as a master switch for angiogenesis $(69,70)$. Furthermore, HIF-1 $\alpha$ activation contributes to the pathogenesis of MM by stimulating angiogenesis via upregulation of IL8 and VEGF-A (71). In MM, impairment of cell-adhesion and promotion of invasion and metastasis is caused by binding of HIF- $1 \alpha$ to the promoter of zinc finger transcription factor SNAI1 leading to decreased expression of E-cadherin $(72,73)$.

miRs affecting proteasomal degradation

miR-125a. miR-125a (Figure 2) expression is low in MM cell lines and tissues in comparison to matching control cells and tissues (74). Overexpression of miR-125a in NCI-H929 and U266 MM cells decreases cell viability and colonyforming ability by promotion of apoptosis (74). Overexpression of miR-125a in a mouse xenograft model inhibits TG (74). Ubiquitin-specific peptidase 5 (USP5) was identified as a direct target of miR-125a (74). USP5 cleaves linear and branched ubiquitin polymers and therefore inhibits 


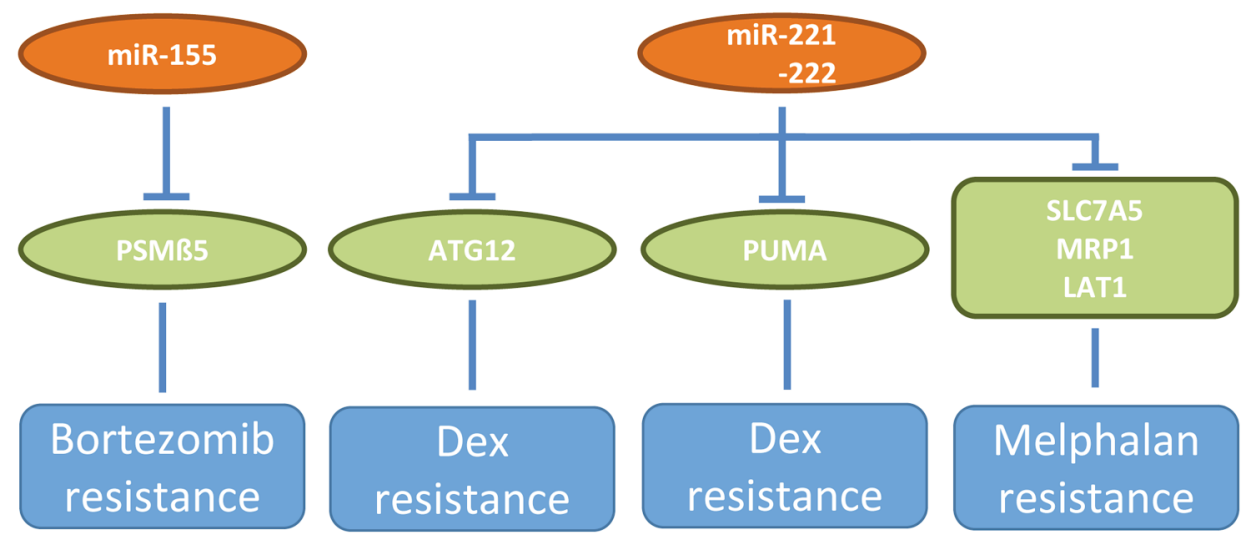

Figure 3. miRs involved in resistance to bortezomib, dexamethasone and melphalan in preclinical in vivo models of multiple myeloma. Up-regulation of miR-155 mediates bortezomib resistance, whereas down-regulation of miR-221/222 is involved in dexamethasone and melphalan resistance. ATG12: Autophagy-related 12; Dex: dexamethasone; LAT1: large neutral amino transporter 1; MRP1: multidrug resistance associated protein 1; PSM 3 5: proteasome subunit $\beta$ type 5; PUMA: 553 up-regulated modulator of apoptosis; SCL7A5: solute carrier family 7, member 5.

the proteosomal pathway in MM cells $(75,76)$. Inhibition of USP5 has been shown to result to degradation of transcription factor c-MAF and apoptosis MM cells (77).

miR-155. miR-155 (Figure 2) is down-regulated in MM patient-derived plasma cells compared to healthy plasma cells (78). Synthetic miR-155 mimics trigger antiproliferative and pro-apoptotic effects in RPMI 8226 and OPM2 MM cells (78). OPM2 cells transduced with miR-155 exhibit moderate inhibiton of TG after subcutaneous implantation into nude mice, however combination with bortezomib greatly enhances in vivo activity (78). Proteosomal subunit PSM $\beta 5$ has been identified as a direct target of miR-155 $(78,79)$ and therefore miR-155 is an inhibitor of proteasome activity. PSM $\beta 5$ is the target of bortezomib and bortezomib resistance in MM is associated with PSM 35 overexpression and polyploidy (80).

miRs with an impact on cell cycle and apoptosis miR-26a. miR-26a (Figure 2) mimics suppress growth of LP1 and U266 MM cells (81). This is achieved by induction of cell-cycle arrest at $\mathrm{G}_{0} / \mathrm{G}_{1}$ phase (81). In vivo, a miR-26a mimetic, injected into subcutaneously established, palpable LP1 xenografts, causes inhibition of TG (81). Cyclindependent kinase 6 (CDK6) was identified as a direct target of miR-26a (81). miR-26a mimics inhibit protein levels of transcription factor E2F-1, p53 and p21 (81). CDK6 phosphorylates TS retinoblastoma $(\mathrm{Rb})$, resulting in release of its binding partner E2F-1 which activates DNA replication (82). CDK4/6 inhibitors palbociclib and ribociclib in combination with aromatase inhibitor letrozole have been approved by the FDA for treatment of hormone receptornegative, advanced-stage breast cancer (83). Palbociclib has been successfully applied in MM therapy, further research has to define the subgroup of patients who receive greatest therapeutic benefit (84).

miRs-137 and -197. Basal expression of miR-137 and miR197 (Figure 2) is significantly higher in normal plasma cells compared to those derived from MM patients and cell lines (85). miRs-137 and -139 are negative regulators of cell viability, colony formation and migration of MM1S and My5 MM cells (85). In miR-137-lentivirus transduced MM1S cells significant inhibition of tumor formation and increased survival in immuno-deficient mice was observed in comparison to the non-transduced cell line (85). Synthetic miR-137, -193 formulated as non-lipid emusion particles injected into palpable MM $1 \mathrm{~S}$ xenografts were able to induce tumor regressions (85). Anti-apoptotic protein myeloid cell leukemia-1 (MCL-1) was identified as a direct target of miR137 (85). MCL-1 plays a complex role in the pathophysiology of MM (86). AZD 5991, a macrocyclic inhibitor of MCL-1 is presently in clinical trials in patients with hematological malignancies (87). Aurora kinase A (AURKA) was identified as another direct target of miR-137 (88). miR-137 overexpression together with bortezomib treatment significantly inhibited TG in a MM xenograft model (88). AURKA is required for the correct duplication and separation of the chromosomes during mitosis, but also exhibits non-mitosis-related functions (89). AURKA inhibitors are presently evaluated in clinical studies in patients with MM (90).

miRs involved in transcription and signaling. miR-30-5p. The members of the miR-30-5p family of miRs (30a,b,c,d,e) exhibit low levels of expression in MM cells compared to normal plasma cells (91). Overexpression of miR-30c reduces proliferation, colony formation, migration and cancer 
stem cell (CSC) generation in H929 and OPM1 MM cells (91). In vivo efficacy of miR-30c was evaluated in three in vivo models (91). TG of subcutaneously implanted H929 cells transduced with miR-30c was inhibited in comparison to the non-transfected cell line. Tail-vein injection of miR30c transduced H929 cells resulted in decreased tumor burden in intestine, spine and skull in comparison to the control cell line. Intraperitoneal delivery of miR-30c using lipid nanoparticles decreased tumor burden and increased survival compared to non-transfected H929 cells (91). B-cell CLL/lymphoma 9 protein (BCL9) was identified as a direct target of the miR-30c $(91,92)$ (Figure 2). BCL9 functions as an essential co-activator of $\mathrm{WNT} / \beta$-catenin transcriptional activity promoting proliferation of several types of cancers (92-94). Aberrant WNT signaling mediating proliferation has been observed in MM cells (95, 96). Identification, preclinical and clinical development of inhibitors of the WNT signaling pathway is pursued by several companies and institutions (97).

$m i R-144-3 p$. Expression of miR-144-3p (Figure 2) in MM cell lines is significantly lower than in plasma samples from healthy individuals (98). MM1S MM cells, transfected with a miR-144-3p mimic, show inhibited cell growth and increased apoptosis (98). MM1S cells transduced with an expression vector for miR-144-3p give rise to decreased tumor size in comparison to the control cell line after subcutaneous implantation into immune-deficient mice (98). Transmembrane tyrosine kinase c-MET was identifed as a direct target of miR-144-3p (98). c-MET is the receptor of hepatocyte growth factor (HGF) and is involved in invasion, migration, proliferation and angiogenesis (99, 100). Dysregulation of c-MET is a hallmark of disease in MM patients (101). Several c-MET inhibitors have been identified and are under preclinical and clinical evaluation (102-105).

miRs involved in epigenetic regulation

miR-145-3p. miR-145-3p (Figure 2) down-regulation is associated with disease progression in MM (106). miR-1453 p exerts a TS function in MM by inducing autophagic cell death (106). miR-145 mimics potentiate anti-MM activity of bortezomib in vitro and in vivo (106). HDAC4 was identified as a direct target of miR-145-3p (106). Suppression of HDAC4 results in up-regulation of pro-apoptotic protein BCL2-like protein 11 (BCL2L11) and causes inactivation of mammalian target of rapamycin complex 1 (mTORC1) (106). HDAC4 is involved in histone deacetylation, chromatin condensation and transcriptional repression (107). An emerging role of histone acetylation in autophagy has been observed (108). It is well documented that HDAC inhibition can induce autophagy in tumor cells (109). However, the physiological consequences of autophagy in cancer are context-dependent (110).
miRs inhibiting several distinct targets including epigeneticsrelated programmes. It has been shown that miR-29b (Figure 2) can function as a TS by targeting epigenetic regulation, modulation of cell proliferation, apoptosis, differentiation, invasion and metastasis and regulation of diverse signaling pathways in tumors (111). The function of miR-29b in cancer is context-dependent, acting as a tumor promoter or as a TS (111). A plethora of miR-29b-related targets have been identified such as key tumor suppressor PTEN, signaling molecules protein kinase B2 (AKT2) and cyclin D2 (CCND2), apoptosis-related molecules BCL2 and MCL1, prometastatic regulators such as VEGF-A, inhibitors of metastasis such as transforming growth factor $\beta$ (TGF $\beta)$, integrins $\alpha 6, \beta 1$ and WNT inhibitory factor-1 (WIF-1), an inhibitor of $\mathrm{WNT} / \beta$ catenin signaling, modulators of epithelial mesenchymal transition (EMT) such as E-cadherin, transcription factors TWIST and SNAIL and extracellular matrix (ECM) remodeling molecules such as collagens (111). Context-dependent functions of specific miRs also have been observed in neuronal development (112). Herein we focus on miR-29b targets which are MM-related. miR-29b targets HDAC4 in several MM cell lines (113). HDAC4 mRNA expression inversely correlates with miR-29b expression in MM samples (113). Silencing of HDAC4 up-regulates miR29b and phenocopies miR-29b effects in MM cells (113). Multiple myeloma growth in vivo was inhibited by targeting HDAC4 (113) and DNA methyltransferases DNMT3A and DNMT3B (115). Neutral-lipid emulsion formulated miR-29b reduces tumor volume by $50 \%$ after intratumoral injection (113), whereas intraperitoneally administered pan-HDAC inhibitor SAHA increases TG inhibition (113). Mechanistic interpretations of the findings have been discussed above (106-109). In addition, it has been shown that disruption of the HDAC4/Rel associated protein B complex blocks MM growth (114). Synthetic miR-29b mimics inhibit cell-cycle progression in MM cells (115). An inverse correlation between expression levels of miR-29b and DNMT3 has been noted in MM cell lines and primary MM samples (115). Synthetic miR-29b mimetics affect DNA methylation after injection as non-lipid emulsion particles into SKMM1 xenografts induced tumor growth (TG) inhibition in comparison to corresponding controls (115). Also, tail vein injection of miR-29b mimetics formulated with non-lipid emulsion particles gave rise to TG inhibition of SKMM1 xenografts (115). miR-29b mimetics were also evaulated in severe combined immuno-deficient (SCID)-synthetic hu mice (116). In this model MM adhere to BMSC in a biopolymeric scaffold in immuno-compromised mice, recapitulating growth of $\mathrm{MM}$ cells. Growth of BM dependent cell line INA-6 in a human BM microenvironment was inhibited by miR-29b (116). It has been shown that DNA methylation and other epigenetic events are involved in MM initiation, progression and high individual variability (117- 
119). Also, DNA methylation has been shown to be involved in inactivation of TS genes in MM (120). H929 and U266 MM cells transfected with miR-29b mimetics display reduced proliferation and increased apoptosis (121). In vivo, H929 cells expressing lentivirus transduced miR-29b show reduced TG after subcutaneous implantation into nude mice in comparison to the non-transduced cell line (121). In this system, Forkhead box protein 1 (FOXP1), a transcription factor, was identified as a direct target of miR-29b (121). FOXP1 functions as a repressor of TS genes (122). FOXP1 is involved in B-cell maturation and differentiation and is expressed in neoplastic plasma cells, but not in their normal counterparts $(123,124)$.

miR-34a modulates a plethora of cancer hallmark-related targets. Up-regulation of miR-34a (Figure 2) in cancer cells is associated with cell-cycle arrest, apoptosis, senescence and TS function $(125,126)$. Proliferation-related targets are cyclin D1, CDK4, CDK6, angiogenesis mediator VEGF, apoptosisrelated BCL2 and NAD-dependent deacetylase Sirtuin (127, 128). A comprehensive list of mir-34a-related targets can be found in $(127,128)$. However, the targets as well as antitumoral or pro-tumoral function of miR-34a are contextdependent $(127,128)$. miR-34a (MRX-34) was the first miR evaluated in clinical studies as substitution therapy. However, clinical studies had to be closed due to multiple immunerelated severe adverse effects $(127,128)$. Herein, we focus on miR-34a in the context of MM. Substitution of miR-34a was shown to correlate with in vivo efficacy in several in several preclinical in MM-related vivo models (129-131). Stable expression of miR-34a inhibits proliferation of p53-mutant SKMM1 cells (129). TG is inhibited in SKMM1 cells after lentiviral transduction of miR-34a in immuno-deficient mice (129). Intratumoral delivery of formulated miR-34a results in inhibition of growth RPMI-8226 MM xenografts (129). Also, systemic delivery of formulated miR-34a inhibits MM xenografts in mice (129). In the SCID-synth-hu mice model $(116,129)$ carrying a 3-dimensional polymeric scaffold reconstituted with human BMSCs and then engrafted with primary MM cells, it was shown that miR-34a mimetics overcome the BM microenvironment-dependent protective effect in vivo displaying reduced tumor infiltration, increased caspase 3 and reduction of Ki67 expression. Further improvement of in vivo efficacy after systemic delivery in MM-related in vivo models was achieved by encapsulation of miR-34a into chitosan/polylactide glycolic acid nanoparticles (130). Combined expression of miR-34a and second mitochondria-derived activator of caspase (SMAC) with a lenti-viral system in RPMI-8226 xenografts resulted in synergistic anti-tumor effects $(131,132)$. Both, miR-34a and SMAC induce mitochondria-initiated apoptosis through release of cytochrome c (131). SMAC is known to bind to inhibitors of apoptosis (IAPs), releasing caspases to activate apoptosis (132). In the preclinical in vivo models for MM as outlined above, it was shown that miR-34a targets validated genes such as BCL2, CDK6, Cyclin D, SIRT1 and VEGF (129-131). No clinical-related parameters are available for miR-34a in MM.

Chemo-resistance. miRs-221/222 (Figure 3) regulate expression of drug transporters solute carrier family 7 member 5/ large neutral amino transporter (SLC7A5/LAT1) and multi-drug resistance protein 1 (ABCC1/MRP1) and through these pathways induce resistance to melphalan (133, 134). In vivo, a 13 mer locked nucleic acid (LNA-i-miR-221) injected intraperitoneally, significantly inhibited growth of subcutaneously implanted, melphalan-resistant U266/LR7 MM xenografts (133). Making use of isogenic dexamethasone (dex)-sensitive and -resistant MM cell lines MM1S and MM1R, pro-apoptotic protein PUMA was identified as a mediator of dex resistance (135). Enforced expression of miR-221/222 in MM1S induces dex resistance in vivo (135). ASO directed against miR-221 abrogates dex resistance of MM1R cells in vivo and increases survival of MM1R xenografts in vivo (135). In another system it was shown that inhibitors of miR-221/222 increased the expression of its target autophagy-related 12 (ATG12) and functionally induced autophagy and cell death in MM cells (135, 136). miR-155 (Figure 3) targets proteosomal protein PSM $\beta 5$, the target of bortezomib, thus reducing proteasome activity $(78,79)$. As outlined previously, OPM2 cells transduced with miR-155 exhibit moderate inhibiton of TG after subcutaneous implantation into nude mice, however combination with bortezomib greatly enhances in vivo activity (78). Substitution therapy with miR-155 therefore may antagonize bortezomib resistance in a clinical setting.

\section{Synopsis}

We identified six up-regulated miRs promoting and 12 down-regulated miRs inhibiting in vivo efficacy in MMrelated xenografts. Up-regulated miRs are candidates for inhibition of activity, down-regulated miRs are candidates for substitution therapy, as outlined in greater detail in the next chapter. Down-regulation of the target of miR-17-5p, FPN1, correlates with bad prognosis in MM patients (34) and expression of miR-21 increases during disease progression $(45,137)$. miR-27 and miR-221/222 expression is increased in BM of MM patients and miR-27 expression correlates with bad prognosis $(39,51)$. miRs-20a and -125 b are increased in plasma of $\mathrm{MM}$ patients in comparison to healthy probands $(35,43)$. All the described up-regulated miRs are associated with clinical parameters supporting their further preclinical validation.

Twelve down-regulated miRs are involved in inhibition of $\mathrm{TG}$ in preclinical in vivo models of MM. Their functional 
reconstitution as a mode of therapeutic intervention with MM growth in patients will be outlined in greater detail in the next chapter. miR-34 is de-validated as a target for treatment of cancer because clinical studies were terminated due to strong side-effects $(127,128)$. However, the de-validation holds true only for the specific formulation used in clinical studies. HIF$1 \alpha$, one of the targets of miR-199-5p is involved in the pathogenesis of MM (71). Reduced expression of miRs 15a/16 (59), miR-29b (111-114,138) and miR-145-3p (106) are closely related to progression of MM. For miR-30-5p (91), miRs-125a (74), miR-144-3p (98), miRs-137/197 (85), miR-155 (78) reduced expression in tumor cells compared to corresponding normal cells was shown. With the exception of miR-34 in the specific formulation used in clinical studies, the remaining down-regulated eleven miRs deserve further preclinical validation as targets for inhibition of MM in patients.

\section{Therapeutic Intervention}

As outlined, the therapeutic options of miR-related agents for treatment of $\mathrm{MM}$ are inhibition of miRs or their functional reconstitution both in combination with other agents (139141). miR inhibitors are single-stranded RNAs such as ASO or LNA, 12-25 nts complementary to the corresponding mRNA (142). miR sponges are designed to contain multiple miR-binding sites that compete with the natural mRNA target for binding to the corresponding miR (142). Low-molecular weight inhibitors can interfere with the transcription of the corresponding miRs or secondary structures, however, there are concerns about the specificity of such as compounds (139, 141). Functional reconstitution of miRs can be performed with miR-mimetics or by forced expression of the corresponding miR after tranduction of tumor cells with expression vectors for the miR under study. miR mimetics are chemically synthesized double-stranded RNAs which mimic endogenous miRNAs after transfection into cells (139-141).

It should be kept in mind that MM spreads in the BM, creating small tumors, therefore the disease is referred to as MM (142-146). In some cases one localized tumor forms in a single bone as a plasmacytoma (142-145). In rare cases the disease is found as extracellular myeloma in soft tissues or other organs. In advanced disease, the disease can be located in the blood system as plasma cell leukemia (142-144). For plasmacytoma, intratumoral administration, for MM and plasma cell leukemia systemic administration of miR-related therapeutic agents might be indicated. In the preclinical in vivo experiments outlined in this review, intratumoral injection is the favoured mode of adminstration followed by systemic administration of the corresponding miR-related agents in plasmacytoma. With the exception of plasmacytoma, preclinical validation of miR-related agents should, therefore, focus on systemic administration.

However, various issues have to optimized in the preclinical valdation process, case by case. Critical issues are: Optimization of pharmaco-kinetic and pharmacodynamic properties due to removal by the reticuloendothelial system, renal excretion, entry into the tumor cells and efficiency of intracellular endosomal escape. Further critical issues are hybridization-dependent and -independent side-effects, immunogenicity, haematological and hepatotoxicity and cytokine-release syndrome (147-154). These important aspects are not discussed in this review.

\section{Therapeutic Landscape}

As already outlined, clinical studies in cancer patients with MRX-34 as reconstitution therapy with a miR-34 mimetic have been terminated due to unacceptable side-effects (155). However, clinical studies with a LNA anti-miR-155, COBOMERSEN, revealed a favorable side-effect profile and are presently continued in patients with several types of leukemias and lymphomas (155). However, in patients with MM, miR-155 is down-regulated and therefore treatment with a miR-155 inhibitor is not a therapeutic option. Further setbacks were noticed in clinical studies with miR-related agents in other indications (156). Clinical studies in patients with hepatitis $\mathrm{C}$ infection and kidney disease had to be terminated due to severe side-effects (156). Presently, secondgeneration miRs are clinically evaluated in these indications (156). However, recently Onpattro, also known as Patisiran, a small interfering RNA (siRNA) targeting transerythrin mRNA was approved by the FDA and the European Medicines Agency (EMA) for patients with familial amyloid neuropathy (157, 158). The emerging importance of si-RNA-based therapeutics is emphasized by a recent deal between REGENERON and ALNYLAM covering 39 targets for diseases of the eye, central nervous system and liver (159). However, it should be kept in mind that siRNAs are specific for a single target, whereas miRs hit several targets with impact on several pathwys and signaling networks (160). Therefore, in oncology, miR-related agents might have a conceptual advantage over miR-related agents unless toxicity issues de-validate the corresponding miR-based agent.

\section{Conflicts of Interest}

AN is and UHW was an employee of Roche.

\section{Authors' Contributions}

AN and UHW jointly designed and wrote the manuscript.

\section{References}

1 Hideshima T, Mitsiades C, Tonon G, Richardson and Anderson $\mathrm{KC}$ : Understanding multiple myeloma pathogenesis in the bone marrow to identify new therapeutic targets. Nat Rev Cancer 7: 585-598, 2007. PMID: 17646864. DOI: $10.1038 /$ nrc2189 
2 American Cancer Society: Key statistics about multiple myeloma, 2019. Available at: https://www.cancer.org/cancer/multiplemyeloma/about/key-statistics.html

3 Allegra A, Innao V, Allegra AG, Pugliese M, Di Salvo E, VenturaSpagnolo E, Musolino C and Gangemi S: Lymphocyte subsets and inflammatory cytokines of monoclonal gammopathy of undetermined significance and multiple myeloma. Int J Mol Sci 20, 2019. PMID: 31185596. DOI: 10.3390/ijms20112822

4 Garcia-Gomez A, Sanchez-Guijo F, Del Cañizo MC, San Miguel JF and Garayoa M: Multiple myeloma mesenchymal stromal cells: Contribution to myeloma bone disease and therapeutics. World J Stem Cells 6: 322-343, 2014. PMID: 25126382. DOI: 10.4252/wjsc.v6.i3.322

5 Keats JJ, Chesi M, Egan JB, Garbitt VM, Palmer SE, Braggio E, Van Wier S, Blackburn PR, Baker AS, Dispenzieri A, Kumar S, Rajkumar SV, Carpten JD, Barrett M, Fonseca R, Stewart AK and Bergsagel PL: Clonal competition with alternating dominance in multiple myeloma. Blood 120: 1067-1076, 2012. PMID: 22498740. DOI: 10.1182/blood-2012-01-405985

6 Morgan GJ, Walker BA, Davies FE: The genetic architecture of multiple myeloma. Nat Rev Cancer 12: 335-348, 2012. PMID: 22495321. DOI: $10.1038 / \mathrm{nrc} 3257$

7 Wilcock P and Webster R: The multiple myeloma drug market. Nat Rev Drug Discov 18: 579-580, 2019. PMID: 31367047. DOI: 10.1038/d41573-019-00031-w

8 Morgan GJ and Rasche L: Haematological cancer: Where are we now with the treatment of multiple myeloma? Nat Rev Clin Oncol 14: 461-462, 2017. PMID: 28607521. DOI: 10.1038/ nrclinonc.2017.82

9 Cho SF, Lin L, Xing L, Yu T, Wen K, Anderson KC and Tai YT: Monoclonal antibody: A new treatment strategy against multiple myeloma. Antibodies (Basel) 6: 2017. PMID: 31548533. DOI: 10.3390/antib6040018

10 Szalat R and Munshi NC: Novel agents in multiple myeloma. Cancer J 25: 45-53, 2019. PMID: 30694859. DOI: 10.1097/ PPO.0000000000000355

11 Vallet S, Filzmoser JM, Pecherstorfer M and Podar K: Myeloma bone disease: update on pathogenesis and novel treatment strategies. Pharmaceutics 10, 2018. PMID: 30355994. DOI: 10.3390/pharmaceutics10040202

12 Feinberg D, Paul B and Kang Y: The promise of chimeric antigen receptor (CAR) $\mathrm{T}$ cell therapy in multiple myeloma. Cell Immunol 345: 103964, 2019. PMID: 31492448. DOI: 10.1016/ j.cellimm.2019

13 Swan D, Lynch K, Gurney M and O'Dwyer M: Current and emerging immunotherapeutic approaches to the treatment of multiple myeloma. Ther Adv Hematol 10: 2040620719854171, 2019. PMID: 31244984 . DOI: 10.1177/2040620719854171

14 Bartel DP: Metazoan MicroRNAs. Cell 173: 20-51, 2018. PMID: 29570994. DOI: 10.1016/j.cell.2018.03.006

15 Lee Y, Kim M, Han J, Yeom KH, Lee S, Baek SH and Kim VN: MicroRNA genes are transcribed by RNA polymerase II. EMBO J 23: 4051-4060, 2004. PMID: 15372072. DOI: 10.1038/ sj.emboj.7600385

$16 \mathrm{Du} \mathrm{T}$ and Zamore PD: microPrimer: the biogenesis and function of microRNA. Development 132: 4645-4652, 2005. PMID: 16224044. DOI: $10.1242 / \mathrm{dev} .02070$

17 Bentwich I, Avniel A, Karov Y, Aharonov R, Gilad S, Barad O, Barzilai A, Einat P, Einav U, Meiri E, Sharon E, Spector Y and Bentwich Z: Identification of hundreds of conserved and nonconserved human microRNAs. Nat Genet 37: 766-770, 2005. PMID: 15965474. DOI: $10.1038 / n g 1590$

18 Lin S and Gregory RI: MicroRNA biogenesis pathways in cancer. Nat Rev Cancer 15: 321-333, 2015. PMID: 25998712. DOI: $10.1038 / \mathrm{nrc} 3932$

19 Peter ME: Targeting of mRNAs by multiple miRNAs: the next step. Oncogene 29: 2161-2164, 2010. PMID: 20190803. DOI: 10.1038/onc.2010.59

20 Gong L, Yan Q, Zhang Y, Fang X, Liu B and Guan X: Cancer cell reprogramming: a promising therapy converting malignancy to benignity. Cancer Commun (Lond) 39: 48, 2019. PMID: 31464654.

21 Calin GA and Croce CM: MicroRNA signatures in human cancers. Nat Rev Cancer 6: 857-866, 2006. PMID: 17060945. DOI: $10.1038 /$ nrc1997

22 Di Leva G and Croce CM: Roles of small RNAs in tumor formation. Trends Mol Med 16: 257-267, 2010. PMID: 20493775. DOI: 10.1016/j.molmed.2010.04.001

23 Fasoulakis Z, Daskalakis G, Diakosavvas M, Papapanagiotou I, Theodora M, Bourazan A, Alatzidou D, Pagkalos A and Kontomanolis EN: MicroRNAs determining carcinogenesis by regulating oncogenes and tumor suppressor genes during cell cycle. MicroRNA 2: 89-82, 2019. PMID: 31538910. DOI: $10.2174 / 2211536608666190919161849$

$24 \mathrm{Xu} \mathrm{SJ}, \mathrm{Hu}$ HT, Li HL and Chang S: The Role of miRNAs in immune cell development, immune cell activation, and tumor mmunity: With a focus on macrophages and natural killer cells. Cells 8, 2019. PMID: 31554344. DOI: 10.3390/cells8101140

25 Weidle UH, Dickopf S, Hintermair C, Kollmorgen G, Birzele F and Brinkmann U: The role of micro RNAs in breast cancer metastasis: preclinical validation and potential therapeutic targets. Cancer Genomics Proteomics 15: 17-39, 2018. PMID: 29275360. DOI: $10.21873 /$ cgp.20062

26 Weidle UH, Epp A, Birzele F and Brinkmann U: The functional role of prostate cancer metastasis-related micro-RNAs. Cancer Genomics Proteomics 16: 1-19, 2019. PMID: 30587496. DOI: 10.21873/cgp.20108

27 Weidle UH, Birzele F and Nopora A: MicroRNAs as potential targets for therapeutic intervention with metastasis of non-small cell lung cancer. Cancer Genomics Proteomics 16: 99-119, 2019. PMID: 30850362. DOI: $10.21873 / \mathrm{cgp} .20116$

28 Weidle UH, Birzele F, Kollmorgen G and Nopora A: Potential microRNA-related targets for therapeutic intervention with ovarian cancer metastasis. Cancer Genomics Proteomics 15: 1-15, 2018. PMID: 29275359. DOI: $10.21873 / \operatorname{cgp} .20061$

29 Caracciolo D, Montesano M, Altomare E, Scionti F, Di Martino MT, Tagliaferri $\mathrm{P}$ and Tassone P: The potential role of miRNAs in multiple myeloma therapy. Expert Rev Hematol 11: 793-803, 2018. PMID: 30148649. DOI: 10.1080/17474086.2018.1517041

30 Zhu B, Ju S, Chu H, Shen X, Zhang Y, Luo X and Cong H: The potential function of microRNAs as biomarkers and therapeutic targets in multiple myeloma. Oncol Lett 15: 6094-6106, 2018. PMID: 29731841. DOI: 10.3892/ol.2018.8157

$31 \mathrm{Xu} \mathrm{P,}$ Xia T, Ling Y and Chen B: MiRNAs with prognostic significance in multiple myeloma: A systemic review and metaanalysis. Medicine (Baltimore) 98(33), 2019. PMID: 31415363. DOI: 10.1097/MD.0000000000016711

32 Kong Y, Hu L, Lu K, Wang Y, Xie Y, Gao L, Yang G, Xie B, He W, Chen G, Wu H, Wu X, Zhan F and Shi J: Ferroportin downregulation promotes cell proliferation by modulating the 
Nrf2-miR-17-5p axis in multiple myeloma. Cell Death Dis 10(9): 624, 2019. PMID: 31423010. DOI: 10.1038/s41419-019-1854-0

33 Vlasveld LT, Janssen R, Bardou-Jacquet E, Venselaar H, HamdiRoze H, Drakesmith $\mathrm{H}$ and Swinkels DW: Twenty years of ferroportin disease: A review or an update of published clinical, biochemical, molecular, and functional features. Pharmaceuticals (Basel) 12(3), 2019. PMID: 31505869. DOI, 10.3390/ph12030132

34 Gu Z, Wang H, Xia J, Yang Y, Jin Z, Xu H, Shi J, De Domenico I, Tricot $\mathrm{G}$ and Zhan F: Decreased ferroportin promotes myeloma cell growth and osteoclast differentiation. Cancer Res 75: 22112221, 2015. PMID: 25855377. DOI: 10.1158/0008-5472.CAN14-3804

35 Huang JJ, Yu J, Li JY, Liu YT and Zhong RQ: Circulating microRNA expression is associated with genetic subtype and survival of multiple myeloma. Med Oncol 29: 2402-2408, 2012. PMID: 22447484. DOI: 10.1007/s12032-012-0210-3

36 Wang T, Tao W, Zhang L and Li S: Oncogenic role of microRNA20a in human multiple myeloma. Onco Targets Ther 10: 44654474, 2017. PMID: 28979138. DOI: 10.2147/OTT.S143612

37 Joseph LJ, Le Beau MM, Jamieson GA Jr, Acharya S, Shows TB, Rowley JD and Sukhatme VP: Molecular cloning, sequencing, and mapping of EGR2, a human early growth response gene encoding a protein with "zinc-binding finger" structure. Proc Natl Acad Sci USA 85: 7164-7168, 1988. PMID: 3140236. DOI: 10.1073/pnas.85.19.7164

38 Dzialo-Hatton R, Milbrandt J, Hockett RD Jr and Weaver CT: Differential expression of Fas ligand in Th1 and Th2 cells is regulated by early growth response gene and NF-AT family members. J Immunol 166: 4534-4542, 2001. PMID: 11254710. DOI: $10.4049 /$ jimmunol.166.7.4534

39 Che F, Wan C, Dai J and Chen J: Increased expression of miR-27 predicts poor prognosis and promotes tumorigenesis in human multiple myeloma. Biosci Rep 39(4), 2019. PMID: 30837325. DOI: 10.1042/BSR20182502

40 Yao Y, Luo J, Bian Y, Sun Y, Shi M, Xia D, Niu M, Zhao K, Zeng $\mathrm{L}$, Chen W, Li Z and Xu K: Sprouty2 regulates proliferation and survival of multiple myeloma by inhibiting activation of the ERK1/2 pathway in vitro and in vivo. Exp Hematol 44: 474-482, 2016. PMID: 27016275. DOI: 10.1016/j.exphem.2016.02.009

41 Tan X, Zhu Y, Chen C, Chen X, Qin Y, Qu B, Luo L, Lin H, Wu M, Chen W and Liu Y: Sprouty2 suppresses epithelialmesenchymal transition of human lens epithelial cells through blockade of Smad2 and ERK1/2 Pathways. PLoS One 11: e0159275, 2016. PMID: 27415760.

42 Ding W, Shi W, Bellusci S, Groffen J, Heisterkamp N, Minoo P and Warburton D: Sprouty2 downregulation plays a pivotal role in mediating crosstalk between TGF-beta1 signaling and EGF as well as FGF receptor tyrosine kinase-ERK pathways in mesenchymal cells. J Cell Physiol 212: 796-806, 2007. PMID: 17516543. DOI: $10.1002 /$ jcp. 21078

43 Jiang Y, Ding J, Li J and Chen G3: Effects of microRNA-125b on multiple myeloma cell growth in vitro and in vivo. Oncol Rep 40: 2864-2875, 2018. PMID: 30226579. DOI: 10.3892/or.2018.6668

44 Newton AC and Trotman LC: Turning off AKT: PHLPP as a drug target. Annu Rev Pharmacol Toxicol 54: 537-558, 2014. PMID: 24392697. DOI: 10.1146/annurev-pharmtox-011112-140338

45 Leone E, Morelli E, Di Martino MT, Amodio N, Foresta U, Gullà A, Rossi M, Neri A, Giordano A, Munshi NC, Anderson KC, Tagliaferri $\mathrm{P}$ and Tassone $\mathrm{P}$ : Targeting miR-21 inhibits in vitro and in vivo multiple myeloma cell growth. Clin Cancer Res 19: 2096-
2106, 2013. PMID: 23446999. DOI: 10.1158/1078-0432.CCR-123325

46 Pan X, Wang ZX and Wang R: MicroRNA-21: a novel therapeutic target in human cancer. Cancer Biol Ther 10: 12241232, 2010. PMID: 21139417. DOI: 10.4161/cbt.10.12.14252

47 Lee YR, Chen M and Pandolfi PP: The functions and regulation of the PTEN tumour suppressor: new modes and prospects. Nat Rev Mol Cell Biol 19: 547-562, 2018. PMID: 29858604. DOI: 10.1038/s41580-018-0015-0

48 Papa A and Pandolfi PP: The PTEN-PI3K axis in cancer. Biomolecules 9, 2019. PMID: 30999672. DOI: 10.3390/ biom 9040153

$49 \mathrm{Ju}$ JA and Gilkes DM: RhoB: Team oncogene or team tumor suppressor? Genes (Basel) 9, 2018. PMID: 29385717. DOI: $10.3390 /$ genes 9020067

50 Yuniati L, Scheijen B, van der Meer LT and van Leuwen FN: Tumor suppressors BTG1 and BTG2: Beyond growth control. J Cell Physiol 234: 5379-5389, 2019. PMID: 30350856. DOI: $10.1002 /$ jcp. 27407

51 Di Martino MT, Gullà A, Cantafio ME, Lionetti M, Leone E, Amodio N, Guzzi PH, Foresta U, Conforti F, Cannataro M, Neri A, Giordano A, Tagliaferri $\mathrm{P}$ and Tassone $\mathrm{P}$ : In vitro and in vivo anti-tumor activity of miR-221/222 inhibitors in multiple myeloma. Oncotarget 4: 242-255, 2013. PMID: 23479461. DOI: 10.18632/oncotarget.820

52 Di Martino MT, Gullà A, Gallo Cantafio ME, Altomare E, Amodio N, Leone E, Morelli E, Lio SG, Caracciolo D, Rossi M, Frandsen NM, Tagliaferri $\mathrm{P}$ and Tassone $\mathrm{P}$ : In vitro and in vivo activity of a novel locked nucleic acid (LNA)-inhibitor-miR-221 against multiple myeloma cells. PLoS One 9: e89659, 2014. PMID: 24586944. DOI: 10.1371/journal.pone.0089659

53 Le Sage C, Nagel R, Egan DA, Schrier M, Mesman E, Mangiola A, Anile C, Maira G, Mercatelli N, Ciafrè SA, Farace MG and Agami R: Regulation of the p27(Kip1) tumor suppressor by miR221 and miR-222 promotes cancer cell proliferation. EMBO J 26: 3699-3708, 2007. PMID: 17627278. DOI: 10.1038/sj.emboj. 7601790

54 Frenquelli M, Muzio M, Scielzo C, Fazi C, Scarfò L, Rossi C, Ferrari G, Ghia P and Caligaris-Cappio F: MicroRNA and proliferation control in chronic lymphocytic leukemia: functional relationship between miR-221/222 cluster and p27. Blood 115: 3949-3959, 2010. PMID: 20203269. DOI: 10.1182/blood-2009$11-254656$

55 Matsuoka S, Edwards MC, Bai C, Parker S, Zhang P, Baldini A, Harper JW and Elledge SJ: p57KIP2, a structurally distinct member of the p21CIP1 Cdk inhibitor family, is a candidate tumor suppressor gene. Genes Dev 9: 650-662, 1995. PMID: 7729684. DOI: 10.1101/gad.9.6.650

56 Correia C, Lee SH, Meng XW, Vincelette ND, Knorr KL, Ding H, Nowakowski GS, Dai $\mathrm{H}$ and Kaufmann SH: Emerging understanding of Bcl-2 biology: Implications for neoplastic progression and treatment. Biochim Biophys Acta 1853: 16581671, 2015. PMID: 25827952. DOI: 10.1016/j.bbamcr.2015.03.012

57 Maes A, Menu E, Veirman K, Maes K, Erkerken K and De Bruyne E: The therapeutic potential of cell cycle targeting in multiple myeloma. Oncotarget 8: 90501-90520, 2017. PMID: 29163849. DOI: 10.18632 /oncotarget.18765

58 Gomez-Bougie P and Amiot M: Apoptotic machinery diversity in multiple myeloma molecular subtypes. Front Immunol 4: 467, 2013. PMID: 24391642. DOI: 10.3389/fimmu.2013.00467 
59 Sun CY, She XM, Qin Y, Chu ZB, Chen L, Ai LS, Zhang L and $\mathrm{Hu}$ Y: miR-15a and miR-16 affect the angiogenesis of multiple myeloma by targeting VEGF. Carcinogenesis 34: 426-435, 2013. PMID: 23104180. DOI: 10.1093/carcin/bgs333

60 Dankbar B, Padró T, Leo R, Feldmann B, Kropff M, Mesters RM, Serve H, Berdel WE and Kienast J: Vascular endothelial growth factor and interleukin-6 in paracrine tumor-stromal cell interactions in multiple myeloma. Blood 95: 2630-2636, 2000. PMID: 10753844.

61 Giuliani N, Storti P, Bolzoni M, Palma BD and Bonomini S: Angiogenesis and multiple myeloma. Cancer Microenviron 4: 325-337, 2011. PMID: 21735169. DOI: 10.1007/s12307-0110072-9

62 Daniel KG, Kuhn DJ, Kazi A and Dou QP: Anti-angiogenic and anti-tumor properties of proteasome inhibitors. Curr Cancer Drug Targets 5: 529-541, 2005. PMID: 16305349. DOI: 10.2174/ 156800905774574075

63 D'Amato RJ, Loughnan MS, Flynn E and Folkman J: Thalidomide is an inhibitor of angiogenesis. Proc Natl Acad Sci USA 91: 4082-4085,1994. PMID: 7513432. DOI: 10.1073/ pnas.91.9.4082

64 Dredge K, Marriott JB, Macdonald CD, Man HW, Chen R, Muller GW, Stirling D and Dalgleish AG: Novel thalidomide analogues display anti-angiogenic activity independently of immunomodulatory effects. Br J Cancer 87: 1166-1172, 2002. PMID: 12402158. DOI: 10.1038/sj.bjc.6600607

65 Raimondi L, Amodio N, Di Martino MT, Altomare E, Leotta M, Caracciolo D, Gullà A, Neri A, Taverna S, D'Aquila P, Alessandro R, Giordano A, Tagliaferri $\mathrm{P}$ and Tassone P: Targeting of multiple myeloma-related angiogenesis by miR199a-5p mimics: in vitro and in vivo anti-tumor activity. Oncotarget 2014: 3039-3054, 2014. PMID: 24839982. DOI: 10.18632 /oncotarget.1747

66 Gadiya M and Chakraborty G: Signaling by discoidin domain receptor 1 in cancer metastasis. Cell Adh Migr 12: 315-323, 2018. PMID: 30187813. DOI: 10.1080/19336918.2018.1520556

67 Henriet E, Sala M, Abou Hammoud A, Tuariihionoa A, Di Martino J, Ros M and Saltel F: Multitasking discoidin domain receptors are involved in several and specific hallmarks of cancer. Cell Adh Migr 12: 363-377, 2018. PMID: 29701112. DOI: $10.1080 / 19336918.2018 .1465156$

68 Shen Q1, Cicinnati VR, Zhang X, Iacob S, Weber F, Sotiropoulos GC, Radtke A, Lu M, Paul A, Gerken G and Beckebaum S: Role of microRNA-199a-5p and discoidin domain receptor 1 in human hepatocellular carcinoma invasion. Mol Cancer 9: 227, 2010. PMID: 20799954. DOI: 10.1186/1476-4598-9-227

69 Albadari N, Deng S and Li W: The transcriptional factors HIF-1 and HIF-2 and their novel inhibitors in cancer therapy. Expert Opin Drug Discov 14: 667-682, 2019. PMID: 31070059. DOI: $10.1080 / 17460441.2019 .1613370$

70 Hashimoto T and Shibasaki F: Hypoxia-inducible factor as an angiogenic master switch. Front Pediatr 3: 33, 2015. PMID: 25964891. DOI: 10.3389/fped.2015.00033

71 Giuliani N, Storti P, Bolzoni M, Dalla Palma B and Bonomini S: Angiogenesis and Multiple Myeloma. Cancer Microenvironment 4: 325-337, 2011. PMID: 21735169. DOI: 10.1007/s12307-0110072-9

72 Guarino M, Rubino B and Ballabio G: The role of epithelialmesenchymal transition in cancer pathology. Pathology 39: 305318, 2007. PMID: 17558857. DOI: 10.1080/00313020701329914
73 Zhu GH, Huang C, Feng ZZ, Lv XH and Qiu ZJ: Hypoxiainduced snail expression through transcriptional regulation by HIF-1 $\alpha$ in pancreatic cancer cells. Dig Dis Sci 58: 3503-3515, 2013. PMID: 23979441. DOI: 10.1007/s10620-013-2841-4

74 Wu L, Zhang C, Chu M, Fan Y, Wei L, Li Z, Yao Y and Zhuang W: miR-125a suppresses malignancy of multiple myeloma by reducing the deubiquitinase USP5. J Cell Biochem 121: 642-650, 2020. PMID: 31452281. DOI: 10.1002/jcb.29309, 2019

75 Reyes-Turcu FE, Horton JR, Mullally JE, Heroux A, Cheng X and Wilkinson KD: The ubiquitin binding domain $\mathrm{ZnF}$ UBP recognizes the $\mathrm{C}$-terminal diglycine motif of unanchored ubiquitin. Cell 124: 1197-1208, 2006. PMID: 16564012. DOI: 10.1016/j.cell.2006.02.038

76 Dayal S, Sparks A, Jacob J, Allende-Vega N, Lane DP and Saville MK: Suppression of the deubiquitinating enzyme USP5 causes the accumulation of unanchored polyubiquitin and the activation of p53. J Biol Chem 284: 5030-5041, 2009. PMID: 19098288. DOI: $10.1074 /$ jbc.M805871200

77 Wang S, Juan J, Zhang Z, Du Y, Xu Y, Tong J, Cao B, Moran MF, Zeng Y and Mao X: Inhibition of the deubiquitinase USP5 leads to c-Maf protein degradation and myeloma cell apoptosis. Cell Death Dis 8: e3058. PMID: 28933784. DOI: 10.1038/cddis. 2017.450

78 Amodio N, Gallo Cantafio ME, Botta C, Agosti V, Federico C, Caracciolo D, Ronchetti D, Rossi M, Driessen C, Neri A, Tagliaferri P and Tassone P: Replacement of miR-155 elicits tumor suppressive activity and antagonizes bortezomib resistance in multiple myeloma. Cancers (Basel) 11: pii: E236, 2019. PMID: 30781685. DOI: 10.3390/cancers 11020236

79 Thibaudeau TA and Smith DM: A practical review of proteasome pharmacology. Pharmacol Rev 71: 170-197, 2019. PMID: 30867233. DOI: $10.1124 /$ pr.117.015370

80 Balsas P, Galán-Malo P, Marzo I and Naval J: Bortezomib resistance in a myeloma cell line is associated to PSM $\beta 5$ overexpression and polyploidy. Leuk Res 36: 212-218, 2012. PMID: 21978467. DOI: 10.1016/j.leukres.2011.09.011

$81 \mathrm{Xu}$ YY, Song YQ, Huang ZM, Zhang HB and Chen M: MicroRNA-26a inhibits multiple myeloma cell growth by suppressing cyclin-dependent kinase 6 expression. Kaohsiung J Med Sci 35: 277-283, 2019. PMID: 30897301. DOI: $10.1002 / \mathrm{kjm} 2.12057$

82. Grossel MJ and Hinds PW: Beyond the cell cycle: a new role for Cdk6 in differentiation. J Cell Biochem 97: 485-493, 2006. PMID: 16294322. DOI: 10.1002/jcb.20712

83 Bilgin B, Sendur MAN, Şener Dede D, Akıncı MB and Yalçın B: A current and comprehensive review of cyclin-dependent kinase inhibitors for the treatment of metastatic breast cancer. Curr Med Res Opin 33: 1559-1569, 2017. PMID: 28657360. DOI: 10.1080/03007995.2017.1348344

84 Liu M, Liu H and Chen J: Mechanisms of the CDK4/6 inhibitor palbociclib (PD 0332991) and its future application in cancer treatment (Review). Oncol Rep 39: 901-911, 2018. PMID: 29399694. DOI: 10.3892/or.2018.6221

85 Yang Y, Li F, Saha MN, Abdi J, Qiu L and Chang H: miR-137 and miR-197 induce apoptosis and suppress tumorigenicity by targeting MCL-1 in multiple myeloma. Clin Cancer Res 21: 2399-2411, 2015. PMID: 25724519. DOI: 10.1158/1078-0432.CCR-14-1437

86 Le Gouill S, Podar K, Harousseau JL and Anderson KC: Mcl-1 regulation and its role in multiple myeloma. Cell Cycle 3: 12591262, 2004. PMID: 15467463. DOI: 10.4161/cc.3.10.1196 
87 Fletcher S: MCL-1 inhibitors - where are we now (2019)? Expert Opin Ther Pat 29: 909-919, 2019. PMID: 31566022. DOI: 10.1080/13543776.2019.1672661

88 Qin Y, Zhang S, Deng S, An G, Qin X, Li F, Xu Y, Hao M, Yang Y, Zhou W, Chang H and Qiu L: Epigenetic silencing of miR-137 induces drug resistance and chromosomal instability by targeting AURKA in multiple myeloma. Leukemia 31: 1123-1135, 2017. PMID: 27857131. DOI: 10.1038/leu.2016.325

89 Bertolin G and Tramier M: Insights into the non-mitotic functions of Aurora kinase A: more than just cell division. Cell Mol Life Sci, 2019. PMID: 31562563. DOI: 10.1007/s00018-019-03310-2

90 Lind J, Czernilofsky F, Vallet S and Podar K: Emerging protein kinase inhibitors for the treatment of multiple myeloma. Expert Opin Emerg Drugs 24: 133-152, 2019. PMID: 31327278. DOI: 10.1080/14728214.2019.1647165

91 Zhao JJ, Lin J, Zhu D, Wang X, Brooks D, Chen M, Chu ZB, Takada K, Ciccarelli B, Admin S, Tao J, Tai YT, Treon S, Pinkus G, Kuo WP, Hideshima T, Bouxsein M, Munshi N, Anderson K and Carrasco R: miR-30-5p functions as a tumor suppressor and novel therapeutic tool by targeting the oncogenic Wnt/ $\mathrm{\beta}$ catenin/BCL9 pathway. Cancer Res 74: 1801-1813, 2014. PMID: 24599134. DOI: 10.1158/0008-5472.CAN-13-3311-T

92 Zhao JJ and Carrasco RD: Crosstalk between microRNA30a/b/ $\mathrm{c} / \mathrm{d} / \mathrm{e}-5 \mathrm{p}$ and the canonical Wnt pathway: implications for multiple myeloma therapy. Cancer Res 74: 5351-5358, 2014. PMID: 25228654. DOI: 10.1158/0008-5472.CAN-14-0994

93 Mani M, Carrasco DE, Zhang Y, Takada K, Gatt ME, DuttaSimmons J, Ikeda H, Diaz-Griffero F, Pena-Cruz V, Bertagnolli M, Myeroff LL, Markowitz SD, Anderson KC and Carrasco DR: BCL9 promotes tumor progression by conferring enhanced proliferative, metastatic, and angiogenic properties to cancer cells. Cancer Res 69: 7577-7586, 2009. PMID: 19738061. DOI: 10.1158/0008-5472.CAN-09-0773

94 Takada K, Zhu D, Bird GH, Sukhdeo K, Zhao JJ, Mani M, Lemieux M, Carrasco DE, Ryan J, Horst D, Fulciniti M, Munshi NC, Xu W, Kung AL, Shivdasani RA, Walensky LD and Carrasco DR: Targeted disruption of the BCL9/ $\beta$-catenin complex inhibits oncogenic Wnt signaling. Sci Transl Med 4: 148ra117, 2012. PMID: 22914623. DOI: 10.1126/scitranslmed. 3003808

95 Derksen PW, Tjin E, Meijer HP, Klok MD, MacGillavry HD, van Oers MH, Lokhorst HM, Bloem AC, Clevers H, Nusse R, van der Neut R, Spaargaren M and Pals ST: Illegitimate WNT signaling promotes proliferation of multiple myeloma cells. Proc Natl Acad Sci USA 101: 6122-6127, 2004. PMID: 15067127. DOI: 10.1073/pnas.0305855101

96 van Andel H, Kocemba KA, Spaargaren M and Pals ST: Aberrant Wnt signaling in multiple myeloma: molecular mechanisms and targeting options. Leukemia 33: 1063-1075, 2019. PMID: 30770859. DOI: 10.1038/s41375-019-0404-1

97 Kahn M: Can we safely target the WNT pathway? Nat Rev Drug Discov 13: 513-532, 2014. PMID: 24981364. DOI: 10.1038/ $\operatorname{nrd} 4233$

98 Zhao Y, Xie Z, Lin J and Liu P: MiR-144-3p inhibits cell proliferation and induces apoptosis in multiple myeloma by targeting c-Met. Am J Transl Res 9: 2437-2446, 2017. PMID: 28559994.

99 Mazzone M and Comoglio PM: The Met pathway: master switch and drug target in cancer progression. FASEB J 20: 1611-1621, 2006. PMID: 16873884. DOI: 10.1096/fj.06-5947rev
100 Skead G and Govender D: Gene of the month: MET. J Clin Pathol 68: 405-409, 2015. PMID: 25987653. DOI: 10.1136/jclinpath2015-203050

101 Rocci A, Gambella M, Aschero S, Baldi I, Trusolino L, Cavallo F, Gay F, Larocca A, Magarotto V, Omedè P, Isaia G, Bertotti A, Liberati AM, Catalano L, De Rosa L, Musto P, Vallone R, Falcone A, Drandi D, Ladetto M, Comoglio PM, Boccadoro M and Palumbo A: MET dysregulation is a hallmark of aggressive disease in multiple myeloma patients. Br J Haematol 164: 841850, 2014. PMID: 24450886. DOI: 10.1111/bjh.12719

102 Comoglio PM, Trusolino L and Boccaccio C: Known and novel roles of the MET oncogene in cancer: a coherent approach to targeted therapy. Nat Rev Cancer 18: 341-358, 2018. PMID: 29674709. DOI: 10.1038/s41568-018-0002-y

103 Gherardi E, Birchmeier W, Birchmeier C and Vande Woude G: Targeting MET in cancer: rationale and progress. Nat Rev Cancer 12: 89-103, 2012. PMID: 22270953. DOI: $10.1038 / \mathrm{nrc} 3205$

104 Zhang QW, Ye ZD and Shi L: c-Met kinase inhibitors: an update patent review (2014-2017). Expert Opin Ther Pat 29: 25-41, 2019. PMID: 30474428. DOI: 10.1080/13543776.2019.1552261

105 Garber K: MET inhibitors start on road to recovery. Nat Rev Drug Discov 13: 563-565, 2014. PMID: 25082276. DOI: 10.1038/ $\operatorname{nrd} 4406$

106 Hongkun Wu, Chang Liu, Qingyuan Yang, Chengde Xin, Juan Du, Fenyong Sun and Lin Zhou: MIR145-3p promotes autophagy and enhances bortezomib sensitivity in multiple myeloma by targeting HDAC4. Autophagy, 2019. PMID: 29893594. DOI: 10.1080/21691401.2018.1464459

107 Wang Z, Qin G and Zhao TC: HDAC4: mechanism of regulation and biological functions. Epigenomics 6: 139-150, 2014. PMID: 24579951. DOI: $10.2217 /$ epi.13.73

108 Bánréti A, Sass M and Graba Y: The emerging role of acetylation in the regulation of autophagy. Autophagy 9: 819-829, 2013. PMID: 23466676. DOI: 10.4161/auto.23908

109 Mrakovcic M, Kleinheinz J and Fröhlich LF: Histone deacetylase inhibitor-induced autophagy in tumor cells: Implications for p53. Int J Mol Sci 18: pii: E1883, 2017. PMID: 30563957. DOI: 10.3390/ijms18091883

110 Panda PK, Mukhopadhyay S, Das DN, Sinha N, Naik PP and Bhutia SK: Mechanism of autophagic regulation in carcinogenesis and cancer therapeutics. Semin Cell Dev Biol 39: 43-55, 2015. PMID: 25724561. DOI: 10.1016/j.semcdb.2015.02.013

111 Yan B, Guo Q, Fu FJ, Wang Z, Yin Z, Wei YB and Yang JR: The role of miR-29b in cancer: regulation, function, and signaling. Onco Targets Ther 8: 539-548, 2015. PMID: 25767398. DOI: 10.2147/OTT.S75899

112 Gao FB: Context-dependent functions of specific microRNAs in neuronal development. Neural Dev 5: 25, 2010. PMID: 20920300. DOI: 10.1186/1749-8104-5-25

113 Amodio N, Stamato MA, Gullà AM, Morelli E, Romeo E, Raimondi L, Pitari MR, Ferrandino I, Misso G, Caraglia M, Perrotta I, Neri A, Fulciniti M, Rolfo C, Anderson KC, Munshi NC, Tagliaferri P and Tassone P: Therapeutic targeting of miR29b/HDAC4 epigenetic loop in multiple myeloma. Mol Cancer Ther 15: 1364-1375, 2016. PMID: 27196750. DOI: 10.1158/ 1535-7163.MCT-15-0985

114 Vallabhapurapu SD, Noothi SK, Pullum DA, Lawrie CH, Pallapati R, Potluri V, Kuntzen C, Khan S, Plas DR, Orlowski RZ, Chesi M, Kuehl WM, Bergsagel PL, Karin M and Vallabhapurapu S: Transcriptional repression by the HDAC4-RelB-p52 complex 
regulates multiple myeloma survival and growth. Nat Commun 6: 8428, 2015. PMID: 26455434. DOI: 10.1038/ncomms9428

115 Amodio N, Leotta M, Bellizzi D, Di Martino MT, D’Aquila P, Lionetti M, Fabiani F, Leone E, Gullà AM, Passarino G, Caraglia M, Negrini M, Neri A, Giordano A, Tagliaferri P and Tassone P: DNA-demethylating and anti-tumor activity of synthetic miR-29b mimics in multiple myeloma. Oncotarget 3: 1246-1258, 2012. PMID: 23100393. DOI: 10.18632/oncotarget. 675

116 Calimeri T, Battista E, Conforti F, Neri P, Di Martino MT, Rossi M, Foresta U, Piro E, Ferrara F, Amorosi A, Bahlis N, Anderson KC, Munshi N, Tagliaferri P, Causa F and Tassone P: A unique three-dimensional SCID-polymeric scaffold (SCID-synth-hu) model for in vivo expansion of human primary multiple myeloma cells. Leukemia 25: 707-711, 2011. PMID: 21233838. DOI: 10.1038/leu.2010.300

117 Amodio N, D’Aquila P, Passarino G, Tassone P and Bellizzi D: Epigenetic modifications in multiple myeloma: recent advances on the role of DNA and histone methylation. Expert Opin Ther Targets 21: 91-101, 2017. PMID: 27892767. DOI: 10.1080/ 14728222.2016 .1266339

118 Alzrigat M, Párraga AA and Jernberg-Wiklund H: Epigenetics in multiple myeloma: From mechanisms to therapy. Semin Cancer Biol 51: 101-115, 2018. PMID: 28962927. DOI: 10.1016/ j.semcancer.2017.09.007

119 Glavey SV, Manier S, Sacco A, Salem K, Kawano Y, Bouyssou J, Ghobrial IM and Roccaro AM: Epigenetics in multiple myeloma. Cancer Treat Res 169: 35-49, 2016. PMID: 27696257. DOI: 10.1007/978-3-319-40320-5_4

120 Wong KY and Chim CS: DNA methylation of tumor suppressor protein-coding and non-coding genes in multiple myeloma. Epigenomics 7: 985-1001, 2015. PMID: 26417914. DOI: 10.2217/epi.15.57

121 Wang H, Ding Q, Wang M, Guo M and Zhao Q: miR-29b inhibits the progression of multiple myeloma through downregulating FOXP1. Hematology 24: 32-38, 2019. PMID: 30068241. DOI: 10.1080/10245332.2018.1502961

122 Xiao J, He B, Zou Y, Chen X, Lu X, Xie M, Li W, He S, You S and Chen Q: Prognostic value of decreased FOXP1 protein expression in various tumors: a systematic review and metaanalysis. Sci Rep 6: 30437, 2016. PMID: 27457567. DOI: 10.1038/srep30437

123 Korać P, Peran I, Skrtić A, Ajduković R, Kristo DR and Dominis M: FOXP1 expression in monoclonal gammopathy of undetermined significance and multiple myeloma. Pathol Int 59: 354-358, 2009. PMID: 19432679. DOI: 10.1111/j.14401827.2009.02377.x

124 Campbell AJ, Lyne L, Brown PJ, Launchbury RJ, Bignone P, Chi J, Roncador G, Lawrie $\mathrm{CH}$, Gatter $\mathrm{KC}$, Kusec $\mathrm{R}$ and Banham AH: Aberrant expression of the neuronal transcription factor FOXP2 in neoplastic plasma cells. Br J Haematol 149: 221-230, 2010. PMID: 20096010. DOI: 10.1111/j.13652141.2009.08070.x

125 Farooqi AA, Tabassum S and Ahmad A: MicroRNA-34a: A versatile regulator of myriads of targets in different cancers. Int J Mol Sci 18: pii: E2089, 2017. PMID: 29036883. DOI: 10.3390/ijms18102089

126 Agostini M and Knight RA: miR-34: from bench to bedside. Oncotarget 5: 872-881, 2014. PMID: 24657911. DOI: 10.18632/ oncotarget. 1825
127 O'Callaghan C and Vassilopoulos A: Sirtuins at the crossroads of stemness, aging, and cancer. Aging Cell 16: 1208-1218, 2017. PMID: 28994177. DOI: 10.1111/acel.12685

128 Yamakuchi M, Ferlito M and Lowenstein CJ: miR-34a repression of SIRT1 regulates apoptosis. Proc Natl Acad Sci USA 105: 13421-13426, 2008. PMID: 18755897. DOI: 10.1073/pnas. 0801613105

129 Di Martino MT, Leone E, Amodio N, Foresta U, Lionetti M, Pitari MR, Cantafio ME, Gullà A, Conforti F, Morelli E, Tomaino V, Rossi M, Negrini M, Ferrarini M, Caraglia M, Shammas MA, Munshi NC, Anderson KC, Neri A, Tagliaferri P and Tassone P: Synthetic miR34a mimics as a novel therapeutic agent for multiple myeloma: in vitro and in vivo evidence. Clin Cancer Res 18: 6260-6270, 2012. PMID: 23035210. DOI: 10.1158/1078-0432.CCR-12-1708

130 Cosco D, Cilurzo F, Maiuolo J, Federico C, Di Martino MT, Cristiano MC, Tassone P, Fresta M and Paolino D: Delivery of miR-34a by chitosan/PLGA nanoplexes for the anticancer treatment of multiple myeloma. Sci Rep 5: 17579, 2015. PMID: 26620594. DOI: 10.1038/srep17579

131 Lei W, Wang S, Yang C, Huang X, Chen Z, He W, Shen J, Liu X and Qian W: Combined expression of miR-34a and Smac mediated by oncolytic vaccinia virus synergistically promote antitumor effects in multiple myeloma. Sci Rep 6: 32174, 2016. PMID: 27552933. DOI: 10.1038/srep32174

132 Boddu P, Carter BZ, Verstovsek S and Pemmaraju N: SMAC mimetics as potential cancer therapeutics in myeloid malignancies. Br J Haematol 185: 219-231, 2019. PMID: 30836448. DOI: $10.1111 /$ bjh.15829

133 Gullà A, Di Martino MT, Gallo Cantafio ME, Morelli E, Amodio N, Botta C, Pitari MR, Lio SG, Britti D, Stamato MA, Hideshima T, Munshi NC, Anderson KC, Tagliaferri P and Tassone P: A 13 mer LNA-i-miR-221 inhibitor restores drug sensitivity in melphalan-refractory multiple myeloma cells. Clin Cancer Res 22: 1222-1233, 2016. PMID: 26527748. DOI: 10.1158/10780432.CCR-15-0489

134 Hirschmann-Jax C, Foster AE, Wulf GG, Nuchtern JG, Jax TW, Gobel U, Goodell MA and Brenner MK: A distinct "side population" of cells with high drug efflux capacity in human tumor cells. Proc Natl Acad Sci USA 101: 14228-14233, 2004. PMID: 15381773. DOI: 10.1073/pnas.0400067101

135 Zhao JJ, Chu ZB, Hu Y, Lin J, Wang Z, Jiang M, Chen M, Wang X, Kang Y, Zhou Y, Ni Chonghaile T, Johncilla , Tai YT, Cheng JQ, Letai A, Munshi NC, Anderson KC and Carrasco RD: Targeting the miR-221-222/PUMA/BAK/BAX pathway abrogates dexamethasone resistance in multiple myeloma. Cancer Res 75: 4384-4397, 2015. PMID: 26249174. DOI: 10.1158/00085472.CAN-15-0457

136 Rubinstein AD, Eisenstein M, Ber Y, Bialik S and Kimchi A: The autophagy protein Atg12 associates with antiapoptotic Bcl-2 family members to promote mitochondrial apoptosis. Mol Cell 44: 698-709, 2011. PMID: 22152474. DOI: 10.1016/ j.molcel.2011.10.014

137 Wang JH, Zhou WW, Liu BX, Man DL, Yang ZD, Liu FR and Shang H: Expression and significance of miR-21 in multiple myeloma patients. Genet Mol Res 15, 2016. PMID: 26909911. DOI: $10.4238 / \mathrm{gmr} .15016892$

138 Wang H, Ding Q, Wang M, Guo M and Zhao Q: miR-29b inhibits the progression of multiple myeloma through downregulating FOXP1. Hematology 24: 32-38, 2019. PMID: 30068241. DOI: $10.1080 / 10245332.2018 .1502961$ 
139 Ling H, Fabbri M and Calin GA: MicroRNAs and other noncoding RNAs as targets for anticancer drug development. Nat Rev Drug Discov 12: 847-865, 2013. PMID: 24172333. DOI: $10.1038 / \mathrm{nrd} 4140$

140 Gambari R, Brognara E, Spandidos DA and Fabbri E: Targeting oncomiRNAs and mimicking tumor suppressor miRNAs: New trends in the development of miRNA therapeutic strategies in oncology (Review). Int J Oncol 49: 5-32, 2016. PMID: 27175518. DOI: 10.3892/ijo.2016.3503

141 Broderick JA and Zamore PD: MicroRNA therapeutics. Gene Ther 18: 1104-1110, 2011. PMID: 21525952. DOI: 10.1038/ gt.2011.50

142 Ling H, Fabbri M and Calin GA: MicroRNAs and other noncoding RNAs as targets for anticancer drug development. Nat Rev Drug Discov 12: 847-865, 2013. PMID: 24172333. DOI: $10.1038 /$ nrd 4140

143 Peller PJ: Multiple myeloma. PET Clin 10: 227-241, 2015. PMID: 25829088. DOI: $10.1016 /$ j.cpet.2014.12.008

144 Palumbo A and Anderson K: Multiple myeloma. N Engl J Med 364: 1046-1060, 2011. PMID: 21410373. DOI: 10.1056/ NEJMra1011442

145 Kumar SK, Rajkumar V, Kyle RA, van Duin M, Sonneveld P, Mateos MV, Gay F and Anderson KC: Multiple myeloma. Nat Rev Dis Primers 3: 17046, 2017. PMID: 28726797. DOI: 10.1038/nrdp.2017.46

146 Ghobrial IM: Myeloma as a model for the process of metastasis: implications for therapy. Blood 120: 20-30, 2012. PMID: 22535658. DOI: 10.1182/blood-2012-01-379024

147 MacLeod AR and Crooke ST: RNA therapeutics in oncology: Advances, challenges, and future directions. J Clin Pharmacol 57(Suppl 10): S43-S59, 2017. PMID: 21525952. DOI: 10.1038/ gt.2011.50

$148 \mathrm{Li} \mathrm{Z}$ and Rana TM: Therapeutic targeting of microRNAs: Current status and future challenges. Nat Rev Drug Discov 13: 622-638, 2014. PMID: 25011539. DOI: $10.1038 /$ nrd4359

149 Garofalo M, Leva GD and Croce CM: MicroRNAs as anti-cancer therapy. Curr Pharm Des 20: 5328-5335, 2014. PMID: 24479801. DOI: $10.2174 / 1381612820666140128211346$

150 Malek A, Merkel O, Fink L, Czubayko F, Kissel T and Aigner A: In vivo pharmacokinetics, tissue distribution and underlying mechanisms of various PEI(-PEG)/siRNA complexes. Toxicol Appl Pharmacol 236: 97-108, 2009. PMID: 19371615. DOI: 10.1016/j.taap.2009.01.014

151 Wang AZ, Langer R and Farokhzad OC: Nanoparticle delivery of cancer drugs. Annu Rev Med 63: 185-198, 2012. PMID: 21888516. DOI: 10.1146/annurev-med-040210-162544
152 Rozema DB, Lewis DL, Wakefield DH, Wong SC, Klein JJ, Roesch PL, Bertin SL, Reppen TW, Chu Q, Blokhin AV, Hagstrom JE and Wolff JA: Dynamic PolyConjugates for targeted in vivo delivery of siRNA to hepatocytes. Proc Natl Acad Sci USA 104: 12982-12987, 2007. PMID: 17652171. DOI: 10.1073/ pnas.0703778104

153 Kanasty R, Dorkin JR, Vegas A and Anderson D: Delivery materials for siRNA therapeutics. Nat Mater 12: 967-977, 2013. PMID: 24150415. DOI: 10.1038/nmat3765

154 Nair JK, Willoughby JL, Chan A, Charisse K, Alam MR, Wang Q, Hoekstra M, Kandasamy P, Kel'in AV, Milstein S, Taneja N, O'Shea J, Shaikh S, Zhang L, van der Sluis RJ, Jung ME, Akinc A, Hutabarat R, Kuchimanchi S, Fitzgerald K, Zimmermann T, van Berkel TJ, Maier MA, Rajeev KG and Manoharan M: Multivalent $\mathrm{N}$-acetylgalactosamine-conjugated siRNA localizes in hepatocytes and elicits robust RNAi-mediated gene silencing. J Am Chem Soc 136: 16958-16961, 2014. PMID: 25434769. DOI: 10.1021/ja505986a

155 Seto AG, Beatty X, Lynch JM, Hermreck M, Tetzlaff M, Duvic $\mathrm{M}$ and Jackson AL: Cobomarsen, an oligonucleotide inhibitor of miR-155, co-ordinately regulates multiple survival pathways to reduce cellular proliferation and survival in cutaneous T-cell lymphoma. Br J Haematol 183: 428-444, 2018. PMID: 30125933. DOI: $10.1111 /$ bjh. 15547

156 Jones D: Setbacks shadow microRNA therapies in the clinic. Nat Biotechnol 36: 909-910, 2018. PMID: 30307922. DOI: 10.1038/ nbt1018-909

157 Setten RL, Rossi JJ and Han SP: The current state and future directions of RNAi-based therapeutics. Nat Rev Drug Disc 18: 421-446, 2019. PMID: 30846871. DOI: 10.1038/s41573-019$0017-4$

158 Rizk M and Tüzmen S: Patisiran for the treatment of patients with familial amyloid polyneuropathy. Drugs Today 55: 315-327, 2019. PMID: 31131842. DOI: 10.1358/dot.2019.55.5.2958475

159 Sheridan C: Billion-dollar deal propels RNAi to CNS frontier. Nat Biotechnol 37: 699-706, 2019. PMID: 31267098. DOI: 10.1038/d41587-019-00014-7

160 Lam JK, Chow MY, Zhang Y, Leung SW: siRNA versus miRNA as therapeutics for gene silencing. Mol Ther Nucleic Acids 4: e252, 2015. PMID: 26372022. DOI: 10.1038/mtna.2015.23

Received February 17, 2020

Revised March 9, 2020

Accepted March 11, 2020 